\title{
PENERAPAN PENDEKATAN INQUIRI FISIKA UNTUK MENINGKATKAN HASIL BELAJAR SISWA KELAS XII MIPA SMA NEGERI 3 KOTABUMI
}

\author{
Ahmad Farid. SY \\ ahmadfaridkotabumi@gmail.com
}

SMA Negeri 3 Kotabumi

\begin{abstract}
This study aims to determine whether the application of physics inquiry approach will improve student learning outcomes in Class XII Mathematics 1 Odd Semester 2019/2020 Academic Year at SMA Negeri 3 Kotabumi, North Lampung. The method used in this research is Classroom Action Research which is carried out in two cycles, each cycle consisting of planning, action, observation, and reflection. Data collection techniques used are observation, interviews, tests, photos, and documents. As a result of the improvement actions taken by the teacher from Cycle I to Cycle II, student learning completeness increased from $22 \%$ to $100 \%$, while for the average value also increased from 75.34 to 85.60. This shows that the implementation of KBM with inquiry methods is very effective to improve student learning outcomes.
\end{abstract}

Keyword: Learning Outcomes, Inquiry Approach

\begin{abstract}
Abstrak: Penelitian ini bertujuan untuk mengetahui apakah dengan penerapan pendekatan inquiri fisika akan meningkatkan hasil belajar siswa Kelas XII MIPA 1 Semester Ganjil Tahun Pelajaran 2019/2020 pada SMA Negeri 3 Kotabumi Lampung Utara. Metode yang digunakan dalam penelitian ini adalah Penelitian Tindakan Kelas yang di lakukan dalam dua siklus, setiap siklus terdiri atas perencanaan, tindakan, pengamatan, dan refleksi. Tehnik pengumpulan data yang di gunakan yaitu, observasi, wawancara, tes, fhoto, dan dokumen. Hasil perbaikan tindakan yang dilakukan oleh guru dari Siklus I ke Siklus II, ketuntasan belajar siswa meningkat dari 22\% menjadi 100\%, sedangkan untuk nilai rata-rata juga meningkat dari 75,34 menjadi 85,60. Ini menunjukkan bahwa pelaksanaan KBM dengan metode inquiri sangat efektif untuk meningkatkan hasil belajar siswa.
\end{abstract}

Kata kunci: Hasil Belajar, Pendekatan Inquiri

\section{PENDAHULUAN}

Guru merupakan pemegang peranan yang sangat penting dalam pembelajaran, karena guru bukan hanya sekedar penyampai materi, tetapi lebih dari itu guru dapat dikatakan sebagai sentral pembelajaran. Guru juga sebagai pengatur dan mengarahkan pembelajaran agar dapat dilaksanakan secara efektif juga menarik, sehingga bahan pelajaran yang disampaikan akan membuat siswa merasa senang dan merasa perlu untuk mempelajari bahan pelajaran tersebut.

Hasil pengumpulan data yang penulis lakukan melalui pengamatan pada saat kegiatan belajar mengajar di dalam kelas sebagian besar siswa terlihat kurang terlibat dalam aktivitas belajar. Interaksi belajar mengajar yang terjadi di kelas hanya terjadi satu arah yaitu dari guru ke siswa, 
sedangkan interaksi dengan guru, siswa dengan siswa kurang terjadi. Hal ini terlihat dari sedikitnya siswa yang memberi respon dalam kegiatan belajar mengajar dan hasil belajarnya rendah.

Masalah ini sebenarnya bukan hanya disebabkan siswa saja, tetapi juga dari cara pengelolaan pembelajaran oleh guru. Guru lebih dominan menyampaikan pelajaran dan kurang memberikan kesempatan kepada siswa untuk aktif berinteraksi, guru kurang memperhatikan perbedaan kemampuan dalam diri siswa sehingga guru memperlakukan siswa secara sama.

Oleh karena itu perlu adanya perbaikan dalam kegiatan pembelajaran yaitu dengan pendekatan inquiri. Dengan pendekatan inquri diharapkan seluruh siswa akan aktif belajar dan berdiskusi untuk mengambil konsep-konsep yang dipelajarinya. Dengan demikian interaksi tiga arah akan terlaksana dalam PBM, yaitu siswa dengan siswa, siswa dengan guru serta siswa dengan lingkungannya. Inquiri sebagai metode mengajar yang dilakukan oleh guru untuk memotivasi atau menggiring cara berpikir siswa dalam suatu materi pelajaran yang memudahkan siswa untuk memahami konsep-konsep yang diberikan oleh gurunya.

Clifford (1976) mengemukakan bahwa inquiri mempunyai lima tahapan, yaitu: merumuskan masalah, merumuskan hipotesis, mengumpulkan data, mengevaluasi fakta, dan membuat kesimpulan, yang telah menjadi ketentuan sehingga disebut metode ilmiah dari pemecahan masalah.

\section{METODE}

Penelitian ini merupakan Penelitian Tindakan Kelas (classroom action reseach) yaitu suatu penelitian yang dilakukan secara sistematis reflektif terhadap berbagai tindakan yang dilakukan guru sekaligus sebagai peneliti, sejak disusunnya suatu perencanaan sampai penilaian terhadap tindakan nyata di dalam kelas yang berupa kegiatan belajar mengajar dalam memperbaiki kondisi pembelajaran yang dilakukan secara berulang-ulang (siklus) sampai ditemukan tindakan yang tepat (ideal) dalam rangka mencapai tujuan.

Dalam penelitian ini menggunakan dua siklus dengan tahapan-tahapan masingmasing siklus terdiri atas perencanaan, pelaksanaan, pengamatan, dan refleksi. Instrumen yang digunakan Perangkat pembelajaran yang terdiri dari program tahunan, program semester dan RPP, Lembar observasi, Lembar kuesioner siswa dan alat evaluasi. Pada tiap siklus guru melaksanakan tindakan seperti yang direncanakan dan diamati oleh kolaborator, dan mendiskripsikan aktifitas siswa yang diperoleh sebagai refleksi terhadap tindakan yang dilakukan guru. 


\section{HASIL DAN PEMBAHASAN}

Pada siklus II, siswa lebih aktif dalam mengikuti KBM bila dibandingkan dengan siklus I. Peningkatan keaktifan siswa ini dikarenakan tindakan guru lebih aktif dan kreatif dalam mengarahkan dan membimbing siswa. Sebagai contoh, saat pendahuluan ketika guru memberikan pertanyaan dan siswa masih pasif, maka guru menguraikan lagi pertanyaan yang diajukan sehingga siswa mampu menjawab.

Pada kegiatan ini, guru lebih banyak memberi kesempatan kepada siswa untuk menggunakan alat sendiri. Guru hanya menunjuk dan memperhatikan saja. Untuk pengamatan hasil, guru menjelaskan cara mengamati sedangkan siswa sebagai pengamat. Dengan tindakan ini, siswa menjadi aktip dan mengeti apa yang harus dilakukan, sehingga konsep yang akan ditanamkan, lebih mudah ditangkap dan dipahami siswa. Demikian juga saat pelaksanaan diskusi, guru dengan aktif membimbing dan mengatur jalannya diskusi dengan baik dan aktif.

Pada saat evaluasi (tes lisan), bila siswa belum mampu menjawab, maka guru menguraikan pertanyaanya ke tingkat yang lebih rendah. Tindakan ini dimaksudkan untuk memotivasi siswa agar mau menjawab penanyaan guru dan mampu mem berikan contoh penerapan konsep dalam kehidupan sehari-hari.
Secara keseluruhan langkah-langkah metode inquiri yang efektif hasil perbaikan dari siklus I ke siklus II adalah sebagai berikut.

1. Pendahuluan

Guru menertibkan suasana kelas dengan melakukan beberapa hal diantaranya (a) memperhatikan siswa saat memasuki laboratorium, (b) mengatur posisi duduk siswa, (c) menenangkan siswa sebelum mulai mengajar, dan (d) mengabsen siswa.

Selanjutnya guru menyampaikan prasyarat pengetahuan, yaitu: (a) guru menanyakan pengetahuan yang telah dimiliki siswa yang relevan dengan materi yang akan dibahas, (b) guru sedikit mengulas materi yang terkait dengan pertanyaan prasyarat, dan (c) guru merespon jawaban siswa.

Guru memberikan motivasi: (a) guru menanyakan kejadian sehari-hari yang berhubungan dengan materi yang akan dibahas, (b) guru mendiskripsikan peristiwa sehari-hari yang berkaitan dengan pertanyaan motivasi, (c) guru menanggapi jawaban siswa, (d) guru memberi penjelasan tentang pentingma materi dalam kehidupan sehari-hari.

Guru menyampaikan tujuan pembelajaran: (a) guru menulis tujuan pembelajaran, dan (b) guru menjelaskan tujuan pembelajaran. 
Guru menyiapan alat untuk inquiri: (a) mengeluarkan alat yang akan dipakai dari ruang persiapan, (b) menempatkan alat ditempat yang mudah diamati oleh siswa.

Guru menjelaskan kegunaan alat: (a) memperkenalkan nama alat dan (b) menjelaskan kegunaan alat. Guru menjelaskan cara kerja alat dengan cara (a) menjelaskan cara menggunakan alat, (b) menjelaskan cara membaca skala pada alat.

Guru menjelaskan tehnik keselamatan kerja: (a) menjelaskan keselamatan alat, (b) menjaga alat agar tidak rusak, (c) menginformasikan tentang keselamatan.

\section{Kegiatan Inti}

Guru mengukur menggunakan rangkaian listrik dengan melibatkan siswa: (a) guru menjelaskan kegunaan rangkaian listrik, (b)guru menjelaskan skala pada rangkaian listrik, (c) guru mengukur benda atau dengan melibatkan siswa (d) guru menunjuk

Guru membimbing siswa untuk mencatat hasil pengamatan: (a) menjelaskan hasil pengukuran (b) menyuruh siswa untuk memasukan data hasil pengukuran pada LKS. Selanjutnya guru memimpin diskusi isian LKS: (a) membentuk kelompok kecil, (b) menjelaskan teknis diskusi, (c) guru membimbing siswa secara bergantian tiap kelompok, (d) guru menertibkan diskusi siswa.

Guru membimbing siswa untuk kesimpulan: (a) meminta tiap kelompok untuk mengutarakan hasil diskusi, (b) guru menanggapi hasil diskusi tiap kelompok, (c) guru mengarahkan siswa untuk menarik kesimpulan, (d) guru menulis kesimpulan di papan tulis.

\section{Penutup}

Guru melaksanakan evaluasi test lisan atau test tertulis: (a) guru memberikan pertanyaan atau soal, (b) guru meminta siswa untuk menjawab, (c) guru mendiskripsikan pertanyaan agar siswa siswa mampu menjawab, : (d) guru menangggapi jawaban lisan.

Guru memberikan contoh dalam kehidupan sehari-hari yang sesuai dengan konsep: (a) memberikan contoh penerapan konsep fisika dalam kehidupan sehari-hari, (b) menyuruh siswa mencari contoh penerapan konsep fisika dalam kehidupan sehari-hari, (c) guru menunjukan adanya keterkaitan fisika dengan permasalahanya yang ditemui dalam kehidupan sehari-hari.

Guru meberikan pekerjaan rumah: (a) guru memberikan soal, (b) guru menyuruh siswa mencatat soal, (c) guru menyarankan agar PR dikerjakan sendiri. 
Tabel 1

Hasil Ketuntasan Belajar Materi Gelombang

\begin{tabular}{|c|c|c|c|c|}
\hline \multirow{2}{*}{ Nama Siswa } & \multicolumn{4}{|c|}{ Prosentase Ketuntasan Belajar } \\
\hline & Nilai Siklus 1 & $\%$ & Nilai Siklus 2 & $\%$ \\
\hline Abu Vroiroh Naser & 70 & TT & 80 & $\mathrm{~T}$ \\
\hline Achmad Rasyid & 75 & $\mathrm{~T}$ & 84 & $\mathrm{~T}$ \\
\hline Afrina Zara Kesuma & 75 & $\mathrm{~T}$ & 80 & $\mathrm{~T}$ \\
\hline Amita Citra Utama & 75 & $\mathrm{~T}$ & 86 & $\mathrm{~T}$ \\
\hline Andri Febriyadi Putra & 75 & $\mathrm{~T}$ & 79 & $\mathrm{~T}$ \\
\hline Desna Meilia & 75 & $\mathrm{~T}$ & 91 & $\mathrm{~T}$ \\
\hline Devin Alberto & 75 & $\mathrm{~T}$ & 84 & $\mathrm{~T}$ \\
\hline Dicky Dwi Pradana & 85 & $\mathrm{~T}$ & 95 & $\mathrm{~T}$ \\
\hline Dina Arisanti Azzahra & 70 & TT & 79 & $\mathrm{~T}$ \\
\hline Dwi Sulis Tama & 70 & $\mathrm{TT}$ & 84 & $\mathrm{~T}$ \\
\hline Eka Mai Saputra & 75 & $\mathrm{~T}$ & 79 & $\mathrm{~T}$ \\
\hline Fathur Rahman Rais & 75 & $\mathrm{~T}$ & 87 & $\mathrm{~T}$ \\
\hline Haifa Amanda & 75 & $\mathrm{~T}$ & 92 & $\mathrm{~T}$ \\
\hline Made Bayu Prayoga & 80 & $\mathrm{~T}$ & 93 & $\mathrm{~T}$ \\
\hline M. Agha Ardanata & 85 & $\mathrm{~T}$ & 89 & $\mathrm{~T}$ \\
\hline M. Moza Faqih Andaly & 70 & TT & 80 & $\mathrm{~T}$ \\
\hline M. Iqbal Noer Faizi & 75 & $\mathrm{~T}$ & 84 & $\mathrm{~T}$ \\
\hline M. Nirwan Fachrozi & 75 & $\mathrm{~T}$ & 80 & $\mathrm{~T}$ \\
\hline Nandita Aisha & 75 & $\mathrm{~T}$ & 86 & $\mathrm{~T}$ \\
\hline Nur Azzahra & 75 & $\mathrm{~T}$ & 79 & $\mathrm{~T}$ \\
\hline Rangga Putra Yudha & 75 & $\mathrm{~T}$ & 91 & $\mathrm{~T}$ \\
\hline Ratu Jelita Pembayun & 75 & $\mathrm{~T}$ & 84 & $\mathrm{~T}$ \\
\hline Rendi Andika Meidi & 85 & $\mathrm{~T}$ & 95 & $\mathrm{~T}$ \\
\hline Ria Angelina & 70 & TT & 79 & $\mathrm{~T}$ \\
\hline Rini Oktari & 70 & $\mathrm{TT}$ & 84 & $\mathrm{~T}$ \\
\hline Riza Azzahra Briliant & 70 & TT & 79 & $\mathrm{~T}$ \\
\hline Sherly Fadhila & 75 & $\mathrm{~T}$ & 87 & $\mathrm{~T}$ \\
\hline Taris Wulan Sari Ka & 75 & $\mathrm{~T}$ & 92 & $\mathrm{~T}$ \\
\hline Tiara Amanda & 75 & $\mathrm{~T}$ & 93 & $\mathrm{~T}$ \\
\hline Veni Alpiona & 85 & $\mathrm{~T}$ & 89 & $\mathrm{~T}$ \\
\hline Vivi Nuraisyah Putri & 75 & $\mathrm{~T}$ & 84 & $\mathrm{~T}$ \\
\hline Wanda Noor Amalia Putri & 85 & $\mathrm{~T}$ & 95 & $\mathrm{~T}$ \\
\hline
\end{tabular}

Dari hasil tindakan perbaikan yang telah dilakukan oleh guru dari Siklus I ke Siklus II, ketuntasan belajar siswa meningkat dari $22 \%$ menjadi $100 \%$. Peningkatan juga terjadi untuk nilai rata- rata dari 75,34 pada siklus I menjadi 85,60 untuk siklus II. Ini menunjukkan bahwa pelaksanaan KBM dengan metode inquiri sangat efektif untuk meningkatkan hasil belajar siswa. 


\section{SIMPULAN DAN SARAN}

\section{Kesimpulan}

Berdasarkan hasil pelaksanaan penelitian tindakan kelas dapat disimpulkan bahwa langkah-langkah metode inquiri yang efektif adalah sebagai berikut.

a. Pendahuluan, yaitu: (a) Guru menertibkan suasana kelas, (b) Guru memberikan prasyarat pengetahuan, (c) Guru memberikan motivasi, dan (d) guru menyampaikan tujuan pembelajaran.

b. Kegiatan inti/pokok, yaitu: (a) Guru memimpin diskusi isian LKS, dan (b) Guru membimbing siswa untuk kesimpulan

c. Penutup, yaitu: (a) Guru melaksanakan evaluasi test lisan atau test tertulis, (b) Guru memberikan contoh dalam kehidupan sehari-hari yang sesuai dengan konsep, dan (c) Guru memberikan pekerjaan rumah.

Hasil belajar Fisika siswa me-ningkat setelah mengikuti kegiatan belajar mengajar yang menggunakan metode Inquiri. Adapun peningkatan prestasi dari siklus I sampai siklus II sebesar $78 \%$.

\section{Saran}

Agar pembelajaran fisika dengan metode lnquiri dapat berhasil dengan baik, maka saran yang dapat disampaikan adalah sebagai berikut.

a. Pihak yang berkompeten dan instansi yang terkait hendaknya segera melakukan pengadaan alat-alat laboratorium fisika, minimal yang dapat digunakan untuk berinquiri di sekolahsekolah yang belum mempunyai alatalat laboratorium sama sekali.

b. Guru harus memiliki ketrampilan menggunakan metode lnquiri yang sesuai dengan langkah-langkah eksperimen dengan inquiri yang efektif.

c. Perlu diadakan penelitian tindakan kelas lanjutan tentang metode ini dengan memperhatikan karakteristik siswa dan lingkungan belajarnya. 


\section{DAFTAR RUJUKAN}

Clifford (1976) Authentic Assesment of Reaching Indonesia Inquiri, U.S. Departemen Education (online), (http:www.inquiry.org/abs2)

Depdikbud. (2000) Penelitian Tindakan Kelas. Bahan Pelatihan Jakarta: Dikdasmen Depdikbud.

Winataputra, Udin S. (2008). Teori Belajar dan Pembelajaran. Jakarta: Universitas Terbuka. 